Людмила Чернышова

Минский лингвистический университет

Переводческий факультет

Кафедра славянских языков

tel. +375 8017 28-0441

e-mail: cherny0101@tut.by

ORCID ID: https://orcid.org/0000-0001-6272-9057

\title{
Семантика словообразовательного гнезда
}

Ключевые слова: словообразовательное гнездо (СГ), семантическое поле, гиперлексема, концептуализация, культурная коннотация.

В структуралистской парадигме, длительное время приоритетной в лингвистике, успешно решались проблемы системности и регулярности словообразования. Однако при таком подходе часто игнорировались многие вопросы семантики, в том числе и семантики словообразования. Справедливо отметить, что проблемы семантических отношений слов в словообразовательном гнезде, их синонимика, антонимика и омонимика в пределах гнезда, направление мотивации никогда не оставались без внимания. Вопросы перехода значений многозначного слова через всю словообразовательную цепь, образование подгнезд в связи с изменением семантики лексем интересовали исследователей в процессе развития дериватологии как науки [Милославский 1975; Улуханов 1977; Янценецкая 1970 и др.]. В современной лингвистике этот подход к проблеме активизировался, и особенно в когнитивном направлении [Земская 1982; Кубрякова 1981; Петрухина 2002; Полянчук 2008 и др.].

Когнитивисты рассматривают словообразовательную систему русского языка как отражение картины мира, ментальной деятельности человека в языке, а сама картина мира традиционно понимается как ис- 
торически сложившаяся в обыденном сознании данного языкового коллектива и отраженная в языке совокупность представлений о мире, определенный способ концептуализации действительности. Исследование словообразовательной системы русского языка с позиции когнитивизма, развитие теории словообразовательной семантики неразрывно связано с именем Е.С. Кубряковой [Кубрякова 1988].

Актуальность этой парадигмы подтверждается и лексикографической практикой - недавним появлением толковых словообразовательных словарей русского языка И.А. Ширшова и Т.Ф. Ефремовой, где производные слова представлены с одновременной фиксацией их лексических значений [Ширшов 2004; Ефремова 2000, 2005].

Следует, однако, заметить, что вопрос семантики словообразовательного гнезда нельзя признать исследованным в достаточной мере. Языковая картина мира создается в ходе номинативной деятельности, характер соотношения концептуальной и языковой систем целесообразно изучать постоянно, исследуя саму эту деятельность и устанавливая в процессе такого анализа ее направление в обозначении определенных фрагментов мира, реальные средства и приемы номинации, национальный и культурный колорит происходящего, причины, мотивы и интенции говорящих.

Итак, словообразовательные гнезда, являясь важнейшей единицей структурной организации лексического фонда языка, могут рассматриваться как способ воплощения знаний человека об окружающем его мире в языке, таким образом, это сложные репрезентанты концептуальных значений. Каждое употребление слова, в том числе и слова производного, вызывается необходимостью объективировать, выявлять, реализовать его значения как ту часть сведений о мире или информации о нем, которая была получена человеком в процессе познавательной и общественной деятельности и которая соотносится в языке с данным словесным знаком [Кубрякова 1981, 6]. Словообразовательное гнездо представляет собой объединение однокоренных слов не только на основе их деривационного родства (отношений производности), но и на основе семантических связей, лексической мотивированности. Семантические связи между однокоренными лексемами в гнезде разнообразны. K одному и тому же производному слову нередко протягиваются смысловые нити от разных лексических единиц.

Словообразовательное гнездо является основной единицей структурно-смысловой организации лексического фонда языка, поэтому анализ его особенностей немыслим без анализа концептуально-семантических полей. Представляя собой гиперлексему, СГ являются макси- 
мально крупными единицами вербализованной репрезентации концептов в языке. Исследуя гнезда, можно, анализируя значение производных, извлечь такую скрытую, имплицитную, информацию, которую на уровне непроизводного слова трудно эксплицировать. Эта информация достаточно часто национально-специфична.

В данной статье в качестве примера мы использовали словообразовательное гнездо кровь, представленное «Словообразовательным словарем русского языка» А.Н. Тихонова [Тихонов 1985]. Эта объемная структура состоит из 142 производных, она включает как словообразовательные цепи, так и словообразовательные парадигмы. В рамках подобной довольно сложной конструкции можно проследить сложную сеть семантических соответствий между компонентами: непроизводным (базовым) словом - вершиной данного гнезда (кровь) и лексемами словообразовательной парадигмы.

Лексема кровь, возглавляющая эту структуру, не однозначна и культурно специфична, более того, можно утверждать, что это универсальный культуроформирующий символ, и это настолько очевидно, что толковые словари, как старые, так и новейшие фиксируют культурные смыслы. Согласно словарю Т.Ф. Ефремовой, кровь - это жидкость красного цвета, циркулирующая в организме человека или животного, доставляющая питательные вещества к тканям и уносящая продукты их распада. Кроме этой основной семы, лексеме принадлежат три переносных значения: перен. разг. убийство; перен. близкое, единокровное родство // происхождение // устар. потомок; перен. страсти, темперамент [Ефремова 2000].

Другие лексикографические источники определяют семантический объем лексемы несколько иначе. Словарь С.И Ожегова дает четыре значения: 1. У человека и позвоночных животных: обращающаяся в кровеносной системе красная жидкость (жидкая ткань), обеспечивающая питание и обмен веществ всех клеток; 2. перен. Об узах родства, родственных, давних родовых связях; 3. перен. Кровавое убийство, кровопролитие; 4. О породе животных. Хороших, чистых кровей (хорошей породы) [Ожегов 1984], а С.А. Кузнецова два: 1. Жидкость, которая движется по кровеносным сосудам организма и обеспечивает питание его клеток и обмен веществ в нём; 2. О близком родстве, родовых связях или общем происхождении [Кузнецов 2008]. Во всех дефинициях совпадает первое, прямое значение слова, а также переносное 'родство', в словаре Т.Ф. Ефремовой и С.А. Кузнецова зафиксирован оттенок семантики 'происхождение', Т.Ф. Ефремовой и С.И. Ожегова - 'кровопролитие, убийство', только в словаре С.И. Ожегова встре- 
чаем кровь - 'порода животных', Т.Ф. Ефремовой - 'страсти, темперамент'. Таким образом, авторитетные лексикографические источники включают в дефиниции культурную информацию, хотя, к сожалению, не исчерпывающую.

По происхождению кровь - это общеславянское слово индоевропейской природы. Словарь Г.А. Крылова связывает русское слово с древнеиндийским kravis 'сырое мясо', литовским kraujas 'кровь', латинским kruor 'кровь, текущая из раны' [Крылов 2005]. Таким образом, этимология русского слова, в первую очередь, связывается с прямым значением современной лексемы и с семой 'кровопролитие, рана'.

Символизм крови отмечается в словарях символов. Так, интернет-словарь отмечает, что кровь «олицетворяет приниип жизни, душу, силу, силу омолаживаюшую (отсюда жертвоприношения). Красная солярная энергия и вино являются взаимозаменяемыми символами. В Китае кровь и вода рассматриваются как комплементарные символы, представляющие основные принципы инь и ян. В христианском символизме кровь и вода при распятии олицетворяют жизнь тела и жизнь духа. Переступить через кровь значит обрести плодовиmость. На Ближнем Востоке невесты переступали через кровь жертвенной овцы... Выпить чьей-то крови - значит породниться, но таким способом можно вобрать в себя силу врага и тем самым обезопасить его после смерти» [Словарь символов]. Ритуалы и обряды разных народов, связанные с кровью, указывают на интернациональность символа, веру в исключительную мощь этого феномена.

Таким образом, культурные коннотации лексемы могут быть более разнообразными по сравнению со словарным определением. Культурная коннотация является одним из основных компонентов семантической структуры лексемы и одним из факторов воздействия на эволюцию словообразовательного гнезда. Для иллюстрации этого положения обратимся к СГ с вершиной кровь.

Национально-культурная специфика словообразовательного гнезда как лексической микросистемы обнаруживается, с одной стороны, в количестве образующих его единиц и их структурной организации (в соотношении словообразовательных цепочек и парадигм внутри гнезда), с другой стороны, в различии способов словообразования в одной и той же смысловой области.

Границы гнезда подвижны. Гнезда могут пополняться новыми лексическими единицами, но многие слова, наоборот, перемещаются из центра на периферию или совсем выходят из него. Под влиянием различных факторов - лингвистических и экстралингвистических - 
смысловые связи между лексемами, входящими в словообразовательное гнездо, ослабевают или совсем утрачиваются.

В нашем словообразовательном гнезде 8 лексем устаревшие. Некоторые из них потеряли свою актуальность только в определенных значениях: кровь - потомок, кровный - наследственный, чистокровный, полнокровный - отличающийся полнокровием, а некоторые в целом отошли на периферию словарного состава как устаревшие: кровник, кровомщение, кровоочищение, кроворазлитие, полнокровие.

Слова, образующие словообразовательное гнездо, часто неоднородны и в других отношениях. Так, в нашем СГ представлены стилистически разнородные пласты лексики - слова нейтральные (кровь, окровавленныци, кровный, кроваво-красный и др.), книжные (кровообрашение, кровосмешение и др.), разговорные (кровушка, кровишка, кровинка, кровное (сущ.) и др.), просторечные (окровавиться, искровенить), бранные (кровопиец, кровопивеи, кровопийца). Словообразовательное гнездо содержит слова, ограниченные в своем употреблении социально (кровь жарг. - деньги) и слова, не имеющие такого ограничения.

СГ с вершиной кровь включает в себя значительную в количественном отношении группу терминов (41 единица): кровь, кровоток, кровенаполнение, кровозамещение, кровоснабжение, кровотечение, кровопотеря, кровоостанавливаюший, кроветворныи, кровоподтек, белокровие и др. Бо́льшая часть терминологии - медицинские термины, связанные с кровообращением и его нарушением, а также с составом крови. Теплокровные (сущ.), кровососущие (сущ.), кровососка определяют отряд и вид животного (насекомого), кровохлёбка - растения. Основная часть терминологии образована способом сложения или сложно-суффиксальным, например, кроветворение и образованное от него кроветворный, кровотечение и суффиксальный дериват кровоток.

К книжным можно отнести образования с приставкой $n p e-:$ npeхладнокровный, прехладнокровно.

Некоторые лексемы приобретают ту или иную стилистическую окраску в зависимости от значения. Так, сама вершина кровь может быть стилистически нейтральной в значениях 'особая жидкость', 'родство', 'происхождение', разговорной, если употребляется в значении 'убийство', устарелой в значении 'потомок'.

Родственные слова объединяются в одно словарное гнездо на базе семантической общности, которая проявляется в наличии у них общих (стержневых) лексических значений. Наиболее отчетливо выражены родственные связи в однокоренных словах, когда в качестве стержне- 
вого выступают прямые, номинативные значения: кровь - кровушка, кровяной, кровоснабжение, кровенаполнение, окровавленныи, кровоизлияние, кровопотеря и др.

В других случаях словообразовательные связи опираются на переносные значения. Так, семантику 'свой, родственник' поддерживают дериваты кровь, кровник, кровинка, кровинушка, кровнородственный, кровный, единокровный, однокровный, кровосмешение, полукров$\kappa a$ и др., кровь - 'жизнь': полнокровный, бескровный, бескровие, обескровить, обескровливать и др.

Словообразовательное гнездо, воспринимаемое как единица структурно-смысловой организации лексики, помогает эксплицировать не только словообразовательные цепи, которые демонстрируют, как способы деривации способствуют приданию слову дополнительных значений, но и сами семантические цепочки. Лексема кровь, кроме прямого значения 'жидкость, циркулирующая в организме', имеет и другие, в которых репрезентирована концептуализация этого феномена в русском сознании.

В СГ с вершиной кровь нам удалось обнаружить следующие семантические цепочки: 1. цепочка, сформированная прямым значением кровь - жидкость красного цвета, циркулирующая в организме человека или животного, доставляющая питательные вещества к тканям и уносящая продукты их распада, 2. кровь - родство, 3. цепочка, построенная на семантике оппозиции свой - чужой, 4. кровь - кровопролитие, война, а также агрессия, которую она вызывает, 5. ивет крови, 6. кровь - сила, жизнь, вьразительность, 7. кровь-активность, темперамент.

В первую очередь, хотим остановиться на проявлении оппозиции свой - чужой: родная кровь - чужая кровь. На этой дихотомии построены семантические цепочки кровный, чистокровный, единокровныий и кровосмешение, кровомщение, кровожадный. Переход дериватов в звено свой осуществляется при помощи суффиксации при добавочной коннотации: кровиночка (разг.), кровинушка (разг.), кровинка (разг.). Благодаря суффиксам и стилистической окраске лексемы получают дополнительное значение лица. Семантика свой актуализируется и способом субстантивации: кровные (сущ., например, деньги), кровное (сущ. разг., например, имущество), единокровнье (сущ., родственники). Способ сложения основ (плюс суффиксация и коннотация) способствует проявлению семы 'жестокость, агрессия по отношению к чужому': кровожадный (разг.), кровожадно, кровожадность, кровопиеч (разг.-сниж.), кровопийща, кровопийство (разг.). 
Наличие или отсутствие крови в ком-либо или чем-либо в русском сознании связано с наличием или отсутствием жизненных сил, наступлением смерти в результате кровопотери как в медицинском смысле, так и в смысле насильственной смерти (от ран на поле боя или в драке). С этой семой связано и, казалось бы, не коррелирующее с ней представление о силе и выразительности. Пример полнокровныи и термины типа кроветворный, кровоснабжение и др. актуализируют сему 'жизнь, сила', кровопотеря, кровопролитный, бескровный, обескровить - 'утрата жизни, сил, выразительности'.

Отражены в концептуализации крови в пределах СГ особые значимые качества крови: от терминов белокровие (белая кровь), гнилокровие (гнилая кровь), теплокровные (сущ.) (теплая кровь) до хладнокровие (холодная кровь). Если указанные термины характеризуют заболевание или отряд животных и имеют вполне научное обоснование, то последняя лексема - результат концептуализации: холодная кровь как особенность темперамента. В системе русского языка отражено представление и о горячей крови (человек вспыльчивый, склонный к горячности, раздражению), но оно не репрезентировано в словообразовательном гнезде.

Другое концептуальное качество крови - ее чистота, которое снова актуализирует отношение к своему и чужому. С ним связывается понимание породы, несмешанности крови: чистокровный, полукровка, кровосмешение. Если первый пример имеет отношение к породе животных (лексико-семантический вариант лексемы кровь в словаре С.И. Ожегова), то второй и особенно третий - к человеку.

Цвет крови вследствие функционирования ее как важного культуроносного символа лег в основу колоративов типа кроваво-красный, кроваво-синий, сине-кровавый, бескровный (разг.) 'бледный'.

В результате анализа семантических цепочек обнаружилось, что словарные дефиниции вполне могут быть расширены дополнительными семами:

1. порода (по отношению не только к животным, но и к человеку): чистокровныи, чистокровность, чистокровка (разг.), полукровныи, полукровка, полукровок, кровосмешение, кровосмесительныи;

2. свой: кровно (заинтересован в чем-то), кровные (сущ.) (деньги);

3. агрессия: кровожадный (разг.), кровожадно, кровожадность, кровопивеч (разг.-сниж.), кровопийеч (разг.-сниж.), кровопийща, кровопийство (разг.), кровосос (разг.);

4. цвет - мотивированные основой кровь колоронимы: кровавыи, кроваветь, кроваво-красный, кровав-о-синий, син-е-кровавыци, крова- 
вик (камень). Вспомним в связи с этим положением фразеологизм кровь с молоком;

5. средства, способные воздействовать на состав крови: кровохлеб$\kappa a$ (растение);

6. сила, жизнь: бескровный, бескровийе, обескровить, обескровливать, полнокровный, полнокровно, полнокровность. Приведенные в качестве примеров лексемы используются не только по отношению к людям, но и к некоторым артефактам, например, полнокровный сюжет.

7. темперамент: хладнокровный, хладнокровно, хладнокровность, хладнокровийе, прехладнокровный, прехладнокровно. Как уже упоминалось выше, чрезмерное спокойствие русские связывают с холодной кровью, вспыльчивость - с горячей.

Словообразовательное гнездо с базовой лексемой кровь демонстрирует активность способа сложения не только в образовании терминов: кровопускание, кровоизлияние, кровоподтек, кровоток, кроветворный, но и новых концептуальных значений: кровожадный (жадный до крови $\rightarrow$ жестокий), чистокровнылй (чистая кровь $\rightarrow$ порода), единокровньй (одинаковая кровь $\rightarrow$ родственники), кровосмесительный (смешивать кровь $\rightarrow$ брак между близкими родственниками) и др.

По словообразовательному гнезду можно проследить развитие семантики некоторых лексем, отражающую особенности русской концептуализации. Например, слово бескровие имеет развитую семантическую структуру, оно включает почти все семы, свойственные лексеме кровь: 1. недостаток крови в живом теле, или недостаток здоровой крови, anaemia. 2. в чем или в ком нет крови или ее мало. 3. совершаемый без пролития крови. 4. у кого нет близкого родства, родных; одинокий, безродный, а лексема кровопийеи от значения 'насекомое, питающееся кровью человека или животных' не без помощи коннотации развивает новый смысл: разг.-сниж. 'жестокий, беспощадный человек' [Ефремова 2000]. Коннотация часто является одной из областей зарождения энантиосемии и, таким образом, способствует появлению подгнезд или словообразовательных гнезд с противоположным значением.

Система гнезда эксплицирует случаи отсутствия связи некоторых дериватов с прямым значением ее вершины, так образования кровный, кровно, кровность, кровник (устар.), кровнородственный семантически связаны только со вторым переносныл значением слова кровь ('родство'), а кровопролитие - с первым ('убийство') (по словарю Т.Ф. Ефремовой). 
Таким образом, словообразовательное гнездо с семантической точки зрения представляет собой лексико-семантическое поле, состоящее из микрополей со своими ядерными лексемами, иногда не связанными со значением гиперлексемы и представляющими собой результат концептуализации феномена, что делает его идеальным объектом для экспликации национально-культурных смыслов.

\section{Литература}

Zemskaâ E.A., 1982, Slovoobrazovanie kak deâtel'nost', Moskva. [Земская E.A., 1982, Словообразование как деятельность, Москва.]

Efremova T.F., 2005, Tolkovyj slovar' slovoobrazovatel'nyh edinic russkogo âzyka, Moskva. [Ефремова Т.Ф., 2005, Толковый словарь словообразовательных единии русского языка, Москва.]

Efremova T.F, 2000, Novyj tolkovo-slovoobrazovatel'nyj slovar' russkogo âzyka, Moskva. [Ефремова Т.Ф, 2000, Новый толково-словообразовательный словарь русского языка, Москва.]

Krylov G.A., 2005, Ètimologičeskij slovar' russkogo âzyka, Sankt-Peterburg. [Kрылов Г.А., 2005, Этимологический словарь русского языка, Санкт-Петербург.]

Kubrâkova E.S., 1988, Rol' slovoobrazovaniâ v formirovanii âzykovoj kartiny mira, [v:] Rol' čelovečeskogo faktora $v$ âzyke. Âzyk i kartina mira, Moskva, s. 141-172. [Кубрякова Е.С., 1988, Роль словообразования в формировании языковой картины мира, [в:] Роль человеческого фактора в языке. Язык и картина мира, Москва, с. 141-172.]

Kubrâkova E.S., 1981, Tipy âzykovyh značenij. Semantika proizvodnogo slova, Moskva. [Кубрякова Е.С., 1981, Типы языковых значений. Семантика производного слова, Москва.]

Kuznecov S.A., 2008, Bol'šoj tolkovyj slovar' russkogo âzyka, Sankt-Peterburg. [Кузнецов С.А., 2008, Большой толковый словарь русского языка, Санкт-Петербург.]

Miloslavskij I.S., 1975, O regulârnom priraŝenii značeniâ pri slovoobrazovanii, „Voprosy âzykoznaniâ", № 6, s. 65-72. [Милославский И.С., 1975, О регулярном приращении значения при словообразовании, „Вопросы языкознания", № 6, с. 65-72.]

Ožegov S.I., 1984, Slovar' russkogo âzyka, Moskva. [Ожегов С.И., 1984, Словарь русского языка, Москва.]

Petruhina E.V., 2002, O proizvodnom slove v russkom âzyke s kognitivnoj točki zreniâ, [v:] $S$ lûbov'û k $\hat{a} z y k u$, Moskva-Voronež, s. 206-212. [Петрухина E.B., 2002, О производном слове в русском языке с когнитивной точки зрения, [в:] С любовью к языку, Москва-Воронеж, с. 206-212.] 
Polânčuko B., 2008, Dinamičeskie aspekty analiza proizvodnogo slova, Voronež. [Пoлянчук О.Б., 2008, Динамические аспекты анализа производного слова, Воронеж.]

Slovar' simvolov [Словарь символов], [online], http://enc-dic.com/symbol/Krov-.

Tihonova N., 1985, Slovoobrazovatel'nyj slovar' russkogo âzyka, Moskva. [Tuxoнов А.Н., 1985, Словообразовательный словарь русского языка, Москва.]

Uluhanov I.S., 1977, Slovoobrazovatel'nâ̂ semantika v russkom âzyke i principy eё opisaniâ, Moskva. [Улуханов И.С., 1977, Словообразовательная семантика в русском языке и принципь её описания, Москва.]

Širšov I.A., 2004, Tolkovyj slovoobrazovatel'nyj slovar', Moskva. [Ширшов И.А., 2004, Толковый словообразовательный словарь, Москва.]

Ânceneckaâm N., 1970, Semantičeskie voprosy teorii slovoobrazovaniâ, Tomsk. [Янценецкая М.Н., 1970, Семантические вопросы теории словообразования, Томск.]

\title{
THE FAMILY OF WORDS SEMANTICS
}

\author{
S U M M A R Y
}

As illustrated by the family of words with the top blood the article shows that from the semantic point of view the family of words is a lexical-semantic field, consisting of micro fields with their core lexical units. Sometimes they are not related to the meaning of hyper lexical unit and represent the result of the phenomenon conceptualization, that makes the lexical-semantic field a perfect object for explication of national-cultural senses. 